\title{
Pharmacokinetics of High-Dose Recombinant Erythropoietin in Plasma and Brain of Neonatal Rats
}

\author{
PAMELA A. STATLER, RONALD J. MCPHERSON, LARRY A. BAUER, BRIAN A. KELLERT, AND SANDRA E. JUUL \\ Department of Pediatrics [P.A.S., R.J.M., B.A.K., S.E.J.], Departments of Pharmacy and Laboratory Medicine [L.A.B.], \\ University of Washington, Seattle, Washington 98195
}

\begin{abstract}
Recombinant human erythropoietin (rEpo) is neuroprotective in neonatal models of brain injury. Pharmacokinetic data regarding the penetration of circulating rEpo into brain tissue is needed to optimize neuroprotective strategies. We sought to determine the pharmacokinetics of rEpo given intraperitoneally or subcutaneously in plasma and brain. We hypothesized that 1) exogenous rEpo would penetrate the blood-brain barrier (BBB), 2) brain and plasma Epo would correlate, and 3) brain injury would enhance rEpo penetration. Two hundred and eighty-four 7-d-old control, sham, or brain-injured rats were treated with i.p. or s.c. $r E p o(0,250,2500$, or $5000 \mathrm{U} / \mathrm{kg}$ ) and killed at scheduled intervals. Plasma and brain tissue were collected. Epo concentrations were measured by ELISA. Intraperitoneal injection yielded a faster and greater peak concentration of plasma rEpo (Tmax $3 \mathrm{~h}, \mathrm{Cmax} 10,016 \pm 685 \mathrm{mU} / \mathrm{mL})$ than s.c. injection (Tmax 9 h, Cmax $6224 \pm 753 \mathrm{mU} / \mathrm{mL}$ ). Endogenous brain Epo was below detection even after hypoxia exposure. Systemic rEpo crossed the BBB in a dose-dependent manner, peaked in brain at $10 \mathrm{~h}$, and was increased after brain injury. We conclude that highdose rEpo is detectable in brain for $>20 \mathrm{~h}$ after a single systemic injection. These pharmacokinetic data are valuable for planning of rEpo neuroprotection experiments. (Pediatr Res 61: 671-675, 2007)
\end{abstract}

$\mathrm{B}$ rain injury from hypoxia-ischemia is a significant cause of morbidity and mortality in the term and preterm neonate. Between $20 \%$ and $50 \%$ of asphyxiated newborns with hypoxic-ischemic encephalopathy die during the newborn period. Among survivors, approximately $25 \%$ will have some form of permanent neurodevelopmental handicap, including learning disabilities, mental retardation, cerebral palsy, or epilepsy (1). Given the increasing prevalence of neurodevelopmental impairment and the corresponding need for extended follow-up care, there is a great need for therapeutic intervention $(2,3)$.

A variety of experimental animal models use hypoxiaischemia to study neonatal brain injury. Most commonly, animals are subjected to unilateral common carotid artery ligation followed by systemic hypoxia produced by the inhalation of $8 \%$ oxygen (4). Seven-day-old rat pups are frequently used because this age corresponds neurodevelopmentally to a

Received August 10, 2006; accepted January 18, 2007.

Correspondence: Sandra Juul, M.D., Ph.D., Department of Pediatrics, Division of Neonatology, University of Washington, Box 356320, Seattle, WA 98195; sjuul@u.washington.edu

Supported by the National Institutes of Health (National Institute for Child Health and Human Development) grant no. HD042213-01.

DOI: $10.1203 / p d r .0 b 013 e 31805341 d c$
32-34 wk gestational age human fetus. At this age, cerebral cortical neuronal layering is complete, the germinal matrix is involuting, and white matter has not yet myelinated (5). The brain injury created using this model is limited to the cerebral hemisphere ipsilateral to the carotid artery occlusion and includes damage to the cerebral cortex, striatum (basal ganglia), hippocampus, subcortical, and periventricular white matter (6).

Epo is the primary erythropoietic cytokine and rEpo (200$400 \mathrm{U} / \mathrm{kg} / \mathrm{dose}$ ) is widely used to treat anemia in preterm infants (7). In addition, rEpo is neuroprotective in animal models of brain injury at doses ranging from 1,000 to 30,000 units $/ \mathrm{kg}$ (8). Epo receptors are found in organs throughout the body, including the brain (neurons and glia), eye, heart, lung, liver, small intestine, kidney, adrenals, and placenta (9). Epo functions trophically in a paracrine-autocrine fashion during development and in the normal adult brain, and both Epo and Epo receptor expression are induced by ischemia (10). Both intraperitoneal (i.p.) and subcutaneous (s.c.) administration are effective in rodents. Despite the large molecular size of rEpo $(37 \mathrm{kD})$ and its highly glycosylated, negatively charged structure, a small proportion of systemically administered high-dose rEpo has been measured in CSF in adult primates, near-term sheep, and humans $(11,12)$. The mechanism by which it crosses the BBB is unknown but may include facilitated or simple diffusion $(11,13)$.

The pharmacokinetics of high-dose rEpo in the neonatal rat model are undetermined. Most importantly, it is not known whether route of administration or brain injury affect the concentration of rEpo in brain tissue. We previously determined that systemic administration of high-dose rEpo produces a slow increase of rEpo in CSF (14). More complete pharmacokinetic information will be helpful to determine appropriate plasma target concentrations in future translational studies aimed at reducing brain injury in human neonates. The principle aim of this study was therefore to compare the pharmacokinetics of rEpo $(5000 \mathrm{U} / \mathrm{kg})$ given i.p. or s.c. to both brain-injured (hypoxia-ischemia) and noninjured rat pups. We hypothesized that 1) systemic rEpo would penetrate the BBB and be detectable in brain extracts, 2) Epo concentrations measured in brain extracts and plasma would correlate, and 3)

Abbreviations: AUC, area under the curve; BBB, blood-brain barrier; CSF, cerebral spinal fluid; Epo, erythropoietin; Cmax, maximum Epo concentrations; rEpo, recombinant human Epo; Tmax, time at which Cmax occurred 
brain injury would enhance rEpo penetration across the BBB. Because our methods detect both endogenous rat Epo and exogenous rEpo, we performed dose-concentration experiments to examine whether hypoxia alone, or hypoxic-ischemic brain injury trigger substantial changes in endogenous Epo concentrations. Here, we report that systemic rEpo administration produces a rapid plasma peak and subsequent decline, with a more gradual accumulation of rEpo in brain.

\section{METHODS}

All experimental protocols were approved by the Animal Care and Use Committees at the University of Washington in accordance with U.S. National Institutes of Health guidelines. Timed-pregnant Sprague-Dawley rats (Harlan, Kent, WA) were purchased to permit treatment of rats at postnatal day (P) 7. Animals were housed with a 12-h light/dark cycle and fed ad libitum. Three groups of P7 pups were studied: hypoxia-ischemia braininjured $(n=176)$, noninjured (controls, $n=120)$, and hypoxia-only shams $(n=12)$

Unilateral brain injury was created by cauterizing the right carotid artery of anesthetized (2.5\% isoflurane) P7 rats. After ligation, animals recovered on a warming blanket for $1 \mathrm{~h}$ before exposure to $8 \%$ oxygen $(15 \mathrm{~L} / \mathrm{min})$ for $5 \mathrm{~min}$ to flush the chamber followed by low-flow $8 \%$ oxygen $(5 \mathrm{~L} / \mathrm{min}$ ) for $85 \mathrm{~min}$. The chamber was closely monitored to maintain an ambient temperature of $36^{\circ} \mathrm{C}$. Noninjured control pups were not exposed to ligation or hypoxia. Noninjured sham animals were given an incision only, then exposed to $8 \%$ hypoxia for $90 \mathrm{~min}$.

One 100- $\mu \mathrm{L}$ injection of rEpo (Procrit, Amgen Inc., Thousand Oaks, CA) or saline vehicle was administered to each pup, either i.p. $(n=162)$ or s.c. $(n=146)$. Dosing was based on group litter weight. Doses were either 0 (saline vehicle), 250, 2500, or $5000 \mathrm{U} / \mathrm{kg}$ as indicated in figures and tables. For those animals that underwent brain injury, rEpo was given within $30 \mathrm{~min}$ after hypoxia exposure. After rEpo dosing, pups were returned to their dams until they were euthanized at timed intervals from 0.5 to $48 \mathrm{~h}$ after injection.

Rats were killed by an overdose $(75 \mathrm{mg} / \mathrm{kg}$ ) of Euthasol i.p. (Delmarva Labs, Inc., Midlothian, VA) followed by decapitation. Blood was collected in EDTA-containing $1.5-\mathrm{mL}$ tubes, centrifuged at $25^{\circ} \mathrm{C}(2500 \times g, 10 \mathrm{~min})$, and plasma stored at $-80^{\circ} \mathrm{C}$. Brains were removed, separated into right and left hemispheres, and weighed. Each hemisphere was homogenized in twice the volume for weight $(\mathrm{mL} / \mathrm{g})$ of ice-cold buffer $(0.32 \mathrm{M}$ sucrose, $1 \mathrm{mM}$ EDTA, $5 \mathrm{mM}$ Tris, $0.1 \mathrm{mM}$ phenyl-methyl-sulfonyl-fluoride, $1 \mathrm{mM} \beta$-mercaptoethanol) containing protease inhibitors $(10 \mu \mathrm{M}$ leupeptin and CalBiochem 539131 Cocktail Set $1,1 \mathrm{mg} / \mu \mathrm{L}$ ). Brain homogenates were centrifuged at $4^{\circ} \mathrm{C}(3000 \times \mathrm{g}, 10 \mathrm{~min})$. The first supernatant was spun a second time $(20,000 \times g, 15 \mathrm{~min})$ and the final supernatant was stored at $-80^{\circ} \mathrm{C}$.

Total protein and Epo concentrations were measured using colorimetric assays read on a Beckman-Coulter AD340 plate reader. Epo concentrations in plasma and brain extracts were measured by ELISA using the Quantikine IVD human Epo Immunoassay (R \& D Systems, Minneapolis, MN). This ELISA will detect both endogenous rat Epo and rEpo. A standard curve was done in duplicate using control solutions ranging from 0 to $200 \mathrm{mU} / \mathrm{mL}$ rEpo. Variability was less than $5 \%$ and sensitivity was $0.6 \mathrm{mU} / \mathrm{mL}$. Plasma samples were diluted based on prior experience to fit the ELISA standard range as follows: undiluted for the $0 \mathrm{U} / \mathrm{kg}$ dose, $1: 5$ used with the $250 \mathrm{U} / \mathrm{kg}$ dose, $1: 30$ used for the $2500 \mathrm{U} / \mathrm{kg}$ dose, and 1:50 used for the $5000 \mathrm{U} / \mathrm{kg}$ dose. At 1:50 with a $0.6 \mathrm{mU} / \mathrm{mL}$ sensitivity, a value of $30 \mathrm{mU} / \mathrm{mL}$ or less could be undetectable. All brain extracts were measured undiluted. Total protein concentrations for each brain extract were based on the reduction of bicinchonic acid (BCA assay, Pierce, Rockford, IL). Epo concentrations from brain extracts were normalized to total brain protein and are expressed in $\mathrm{mU} / \mathrm{mg}$ protein.

Pharmacokinetic methods. Model-independent methods were used to compute pharmacokinetic values from mean Epo concentration versus time curves for plasma and brain after s.c. or i.p. injection (15). The elimination rate constant (k) for the plasma data was derived using linear regression to compute the slope of the In plasma Epo concentration versus time graph during the terminal phase. The trapezoidal rule was used to calculate the AUC for the plasma or brain concentration versus time data. For the plasma concentrations, the AUC was extended to infinity by dividing the last measured concentration by the elimination rate constant. The Cmax for the plasma or brain concentration versus time curves were determined by inspection of the data. Tmax was the time that Cmax was attained for each data set. The fraction of Epo in the brain $\left(\mathrm{f}_{\text {brain }}\right.$ ) was computed by dividing the brain concentration by the concurrent plasma concentration for each time point.
Values below the ELISA sensitivity limit $(0.6 \mathrm{mU} / \mathrm{mL})$ were treated as zero based on convention.

The $t_{1 / 2}$ for the plasma concentration versus time curve was computed by taking the quotient of 0.693 and the elimination rate constant. Because the absolute fraction of drug absorption (F) after s.c. or i.p. injection is unknown for this model, clearance $(\mathrm{Cl} / \mathrm{F})$ and volume of distribution $(\mathrm{V} / \mathrm{F})$ were computed as hybrid constants using the following equations: $(\mathrm{Cl} / \mathrm{F})=$ $\mathrm{D} / \mathrm{AUC}_{0-\infty}$ and $(\mathrm{V} / \mathrm{F})=\mathrm{D} /\left(\mathrm{k} \cdot \mathrm{AUC}_{0-\infty}\right)$. The relative amount of drug absorbed after s.c. injection compared with intraperitoneal injection $\left(\mathrm{F}_{\mathrm{rel}}\right)$ was computed by taking the ratio of the respective area under the curve values $\left(\mathrm{AUC}_{(\text {s.c. }) 0-\infty} / \mathrm{AUC}_{(\text {i.p. }) 0-\infty}\right)$.

Data are expressed as means ( \pm SEM) and plotted to illustrate the time course of plasma and brain Epo concentration changes separately. Statistics and correlations between plasma and brain measures were performed using SPSS software (Chicago, IL) with an alpha level of 0.05 , as indicated in Table 3.

\section{RESULTS}

Plasma Epo concentrations were obtained from 308 P7 rat pups. One hundred and twenty pups were noninjured controls, 176 underwent hypoxia-ischemia, and 12 sham rats underwent hypoxia exposure without ischemia (no ligation). Although there is significant homology between rat and human rEpo, baseline plasma Epo concentrations of endogenous rat Epo were below the limit of ELISA detection in P7 rat pups. After injection of rEpo $(5000 \mathrm{U} / \mathrm{kg})$, plasma Epo concentrations increased measurably. There were no differences between the plasma Epo concentrations of control and brain-injured animals and, therefore, plasma values were analyzed for effects of route of administration. Figure 1 plots the difference in rEpo pharmacokinetics for i.p.- and s.c.-injected animals. The Cmax were at $3 \mathrm{~h}$ after i.p., and $9 \mathrm{~h}$ after s.c. injection. Cmax was greater for i.p. than for s.c. injection $(>10,015 \pm 685$ $\mathrm{mU} / \mathrm{mL}$ versus $6224 \pm 753 \mathrm{mU} / \mathrm{mL}$ ). Twenty-four hours after a single injection, plasma Epo concentrations remain elevated $(2022 \pm 566 \mathrm{mU} / \mathrm{mL}$ s.c. and $1093 \pm 442 \mathrm{mU} / \mathrm{mL}$ i.p.). By 48 $\mathrm{h}$ after either i.p. or s.c. injection, plasma Epo concentrations returned to baseline levels. The plasma pharmacokinetic parameters for i.p. versus s.c. dosing are compared in Table 1.

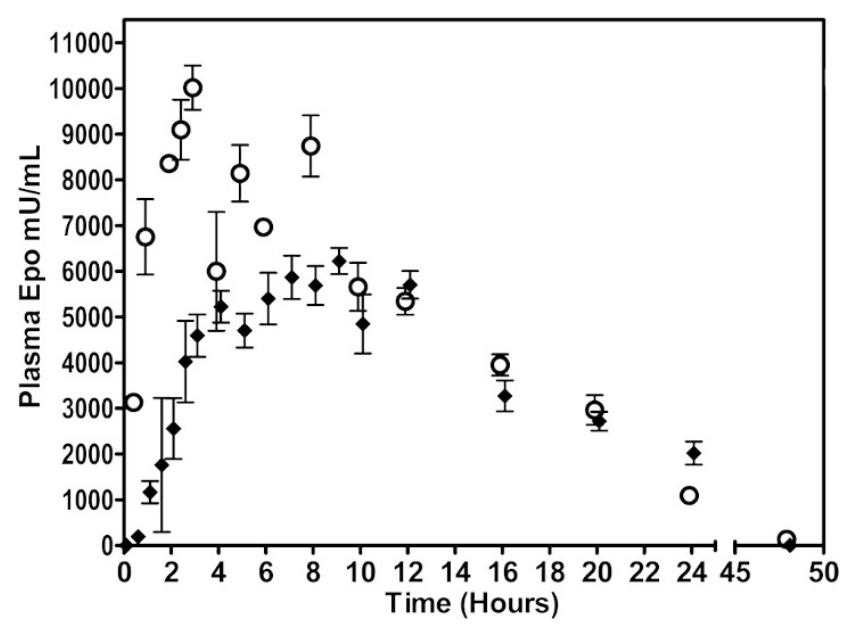

Figure 1. Plasma Epo pharmacokinetics: s.c. vs i.p. dosing. This graph plots the time course of plasma Epo concentrations in rats. The mean ( \pm SEM) plasma Epo concentrations for rats $(n=2-31$ per time point) given a single injection of rEpo $(5000 \mathrm{U} / \mathrm{kg}$ ) by either s.c. or i.p. administration and killed at scheduled time points are shown. Intraperitoneal rEpo administration $(\bigcirc, n=114)$ peaked at $3 \mathrm{~h}(10,015 \pm 685 \mathrm{mU} / \mathrm{mL})$. Subcutaneous rEpo administration $(\diamond, n=146)$ peaked at $9 \mathrm{~h}(6224 \pm 753 \mathrm{mU} / \mathrm{mL})$. 
Table 1. Plasma pharmacokinetics

\begin{tabular}{lccc}
\hline \multicolumn{1}{c}{ Parameter } & s.c. & i.p. & \% Difference \\
s.c. $v$ s i.p.
\end{tabular}

Additional abbreviations used: $\mathrm{Cl} / \mathrm{F}=$ clearance/fraction, $\mathrm{V} / \mathrm{F}=$ volume of distribution, and $\mathrm{F}=$ absolute fraction of drug absorption.

Despite differences in peak concentrations and half life, the AUC is similar for both dosing strategies, with s.c. dosing resulting in a $16 \%$ lower AUC.

Epo was undetectable in brain extracts before rEpo injection. After rEpo injection, however, Epo was detected in the brain tissue of both uninjured control animals and braininjured animals, increasing for $10 \mathrm{~h}$ following injection. Figure 2 plots the time course of normalized Epo measurements in brain extracts for control animals after a single i.p. or s.c. injection of rEpo. The control brain pharmacokinetic values for i.p. and s.c. dosing are listed in Table 2A. Peak Epo concentrations in brain extracts were slightly higher following i.p. injection compared with s.c. injection $(3.3 \pm 1.5$ versus $2.8 \pm 0.8 \mathrm{mU} / \mathrm{mg}$ protein), with the AUC0-24 being $14 \%$ less after s.c. dosing, a value consistent with the plasma kinetics. By $24 \mathrm{~h}$ after either i.p. or s.c. injection, Epo was essentially undetectable in brain extracts.

In brain-injured animals, we examined Epo concentrations in brain extracts by hemisphere (injured versus contralateral) and by route of injection. Figure $3 A$ plots the timed Epo measurements in extracts from injured versus contralateral

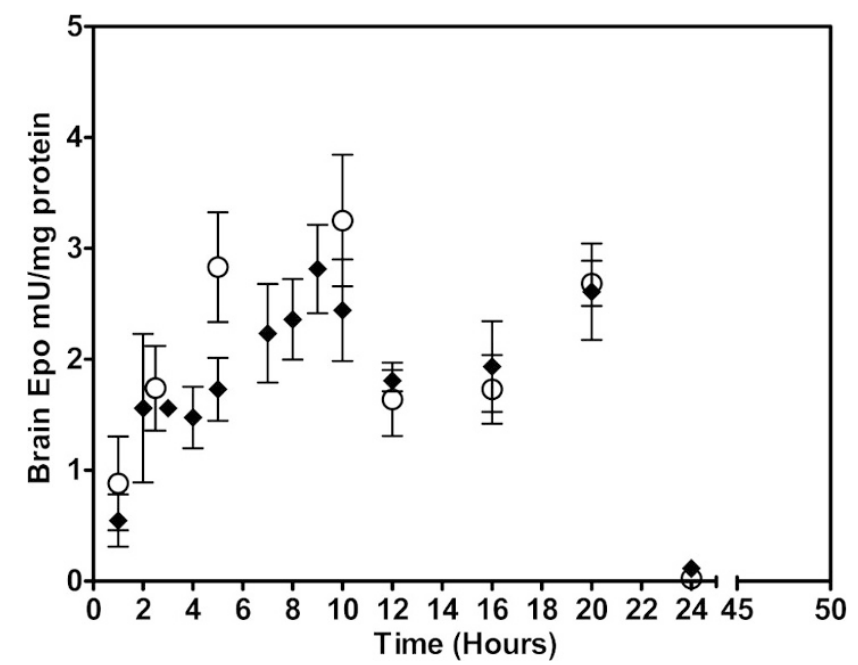

Figure 2. Epo concentrations in control brains: s.c. vs i.p. dosing. This graph plots the time course of accumulation of rEpo in neonatal rat brain after systemic injection $(5000 \mathrm{U} / \mathrm{kg})$. The mean ( \pm SEM) Epo concentrations measured in brain extracts from s.c.- and i.p.-injected control (uninjured) rats ( $n=2-13$ per time point) are reported in $\mathrm{mU} / \mathrm{mg}$ total protein. For i.p. injection $(\bigcirc, n=41)$, rEpo peaked in brain at $10 \mathrm{~h}(3.3 \pm 1.5 \mathrm{mU} / \mathrm{mg}$ protein). For s.c. injection $(\bullet, n=51)$, rEpo peaked at $9 \mathrm{~h}(2.8 \pm 0.8 \mathrm{mU} / \mathrm{mg}$ protein). By 24 h, Epo concentrations from brain extracts were nearing the limit of detection.
Table 2. Brain pharmacokinetics

\begin{tabular}{|c|c|c|c|}
\hline A. & s.c. & i.p. & $\begin{array}{l}\text { \% Difference } \\
\text { s.c. vs i.p. }\end{array}$ \\
\hline \multicolumn{4}{|l|}{ Control brain } \\
\hline $\operatorname{AUC}_{0-24}(\mathrm{U} \cdot \mathrm{h} / \mathrm{g})$ & 45.2 & 52.5 & $-14 \%$ \\
\hline $\mathrm{AUC}_{0-20}(\mathrm{U} \cdot \mathrm{h} / \mathrm{g})$ & 39.7 & 47.1 & $-16 \%$ \\
\hline Cmax $(\mathrm{U} / \mathrm{g})$ & 2.8 & 3.3 & $-15 \%$ \\
\hline $\operatorname{Tmax}(\mathrm{h})$ & 9 & 10 & $-10 \%$ \\
\hline B. & $\begin{array}{c}\text { Injured } \\
\text { hemisphere } \\
\text { s.c. }\end{array}$ & $\begin{array}{c}\text { Contralateral } \\
\text { hemisphere } \\
\text { i.p. }\end{array}$ & $\begin{array}{l}\% \text { Difference } \\
\text { due to injury }\end{array}$ \\
\hline \multicolumn{4}{|l|}{ Injured brain $\mathrm{SC}$} \\
\hline $\mathrm{AUC}_{0-20}(\mathrm{U} \cdot \mathrm{h} / \mathrm{g})$ & 31.1 & 29.9 & $4 \%$ \\
\hline $\mathrm{Cmax}(\mathrm{U} / \mathrm{g})$ & 2.5 & 2.1 & $19 \%$ \\
\hline $\operatorname{Tmax}(\mathrm{h})$ & 7 & 16 & $-56 \%$ \\
\hline \multicolumn{4}{|l|}{ Injured brain IP } \\
\hline $\mathrm{AUC}_{0-20}(\mathrm{U} \cdot \mathrm{h} / \mathrm{g})$ & 41.6 & 27.7 & $50 \%$ \\
\hline $\operatorname{Cmax}(\mathrm{U} / \mathrm{g})$ & 4.1 & 2 & $105 \%$ \\
\hline $\operatorname{Tmax}(\mathrm{h})$ & 10 & 8 & $25 \%$ \\
\hline
\end{tabular}

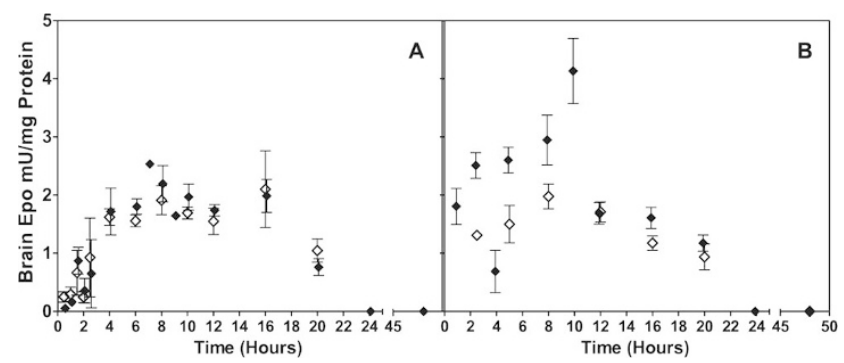

Figure 3. Epo concentrations in injured brains: s.c. vs i.p. dosing. This figure illustrates the time course of accumulation of rEpo in the injured ( ) vs contralateral ( ) brain hemispheres of neonatal rats. Neonatal rats underwent unilateral hypoxic-ischemic lesion followed by systemic injection of rEpo $(5000 \mathrm{U} / \mathrm{kg}$, s.c. or i.p.). The mean $( \pm \mathrm{SEM})$ Epo concentrations measured in brain extracts from each hemisphere are reported in $\mathrm{mU} / \mathrm{mg}$ total protein. Panel $A$ shows data for s.c.-injected ( $n=69,2-14$ per time point) and panel $B$ shows data for i.p.-injected ( $n=71,3-14$ per time point) neonatal rats. Hypoxic-ischemic injury noticeably enhances the penetration of rEpo into brain for i.p.-injected rats (panel $B$ ). At $48 \mathrm{~h}$, all brain extracts were below the Epo detection limit and were assigned a value of zero.

hemispheres after s.c. injections. Epo was detected in both the ipsilateral and contralateral hemispheres, with no appreciable hemispheric differences. Peak brain Epo concentration occurred at $7 \mathrm{~h}$ post injection $(2.5 \pm 0.02 \mathrm{mU} / \mathrm{mg})$ in the injured hemisphere. Epo concentrations in the brain returned to baseline by $24 \mathrm{~h}$ after injection. Figure $3 B$ plots the corresponding data for i.p. rEpo. Table $2 B$ lists the pharmacokinetic parameters for brain-injured animals.

To determine whether hypoxia alone or hypoxia-ischemia stimulates production of endogenous brain Epo, and to test whether the penetration of exogenous rEpo into brain occurs in a dose-dependent manner, experiments were performed to examine the dose-concentration relationship between rEpo dose and plasma and brain Epo concentrations. Based on the pharmacokinetic data described above, a rising phase plasma time point at $2.5 \mathrm{~h}$ and an approximate peak brain time point at $9 \mathrm{~h}$ were chosen to compare multiple lower doses of rEpo. Table 3 lists the dose-concentration relationship of rEpo measured in plasma $(A)$ and right hemisphere brain $(B)$ for hypoxia- 
Table 3. Dose-concentration data for plasma and brain Epo at 2.5 and 9 hours post injection

\begin{tabular}{|c|c|c|c|c|}
\hline & $2.5 \mathrm{~h}$ & Below detection & $9 \mathrm{~h}$ & Below detection§ \\
\hline \multicolumn{5}{|c|}{ A. Plasma Epo $\mathrm{mU} / \mathrm{mL}($ mean $\pm \mathrm{SEM})$} \\
\hline Sham $^{\dagger}$ & $24.9 \pm 10.9$ & $17 \%$ & $9.5 \pm 5.7$ & $17 \%$ \\
\hline Epo $0^{\ddagger}$ & $42.3 \pm 6.7$ & $0 \%$ & $1.2 \pm 0.8$ & $50 \%$ \\
\hline Epo 2,500 & $5070.1 \pm 1095.7 * *$ & $0 \%$ & $4372.0 \pm 608.5^{* *}$ & $0 \%$ \\
\hline \multicolumn{5}{|c|}{ B. Brain Epo $\mathrm{mU} / \mathrm{mg}$ protein (mean $\pm \mathrm{SEM})$} \\
\hline Sham & $0 \pm 0$ & $100 \%$ & $0 \pm 0$ & $100 \%$ \\
\hline Epo 2,500 & $1.26 \pm 0.31^{* *}$ & $0 \%$ & $1.91 \pm 0.5^{* *}$ & $0 \%$ \\
\hline
\end{tabular}

$\dagger$ Shams were incision only (no ligation) then $8 \%$ hypoxia for 90 min but no injections. All other groups underwent ligation and hypoxia and injured (right) brain hemispheres were measured.

$\ddagger$ rEpo was injected after hypoxia in doses of 0 (vehicle), 250 , or 2500 U/kg i.p.

$\S$ Epo ELISA sensitivity is $0.6 \mathrm{mU} / \mathrm{mL}$. Values below detection were treated as $0 \mathrm{mU} / \mathrm{mL}$. There were six animals per group for all conditions $(n=48$ total).

$* p<0.05$ and $* * p<0.01$ compared with same time Epo 0 group using Mann-Whitney $U$ nonparametric tests.

exposed shams (untreated) and hypoxic-ischemic brain-injured animals (rEpo treated). As expected, we found a dose-dependent increase in plasma Epo concentration when comparing 0, 250 and $2500 \mathrm{U} / \mathrm{kg}$ administered i.p. We also demonstrated a small increase in measured endogenous plasma Epo when animals were exposed to hypoxia alone, and this was slightly increased when animals experienced hypoxia-ischemia $24.9 \pm 10.9$ versus $42.3 \pm 6.7$ (Table $3 A$ ). There were no changes in measured brain Epo with either hypoxia or hypoxia-ischemia (Table $3 B$ ). These data confirm that detectable brain Epo requires systemic injection of rEpo at high doses.

Overall, plasma Epo correlated with brain Epo $(r=0.57, p<$ 0.001). This relationship was stronger for brain-injured than for control animals. After brain injury, the correlations were $r=0.71$ $(p<0.001)$ for s.c. dosing, and $r=0.65(p<0.001)$ for i.p. dosing. In controls, the correlations were $r=0.57(p<0.001)$ for s.c. dosing, and $r=0.38(p<0.01)$ for i.p. dosing.

\section{DISCUSSION}

We determined the pharmacokinetics of systemically administered high-dose rEpo to help convert the neuroprotective doses used in animal research into protocols applicable to humans. In neonatal rodents, $5000 \mathrm{U} / \mathrm{kg}$ rEpo is neuroprotective following hypoxic-ischemic injury (16-18). The pharmacokinetic profile relating experimental doses to plasma and brain Epo concentrations will be useful for calculating appropriate doses for human administration. One prior report demonstrated that Epo could be measured directly in brain (19), and we previously measured plasma and CSF concentrations of Epo following $5000 \mathrm{U} / \mathrm{kg}$ rEpo (11). Therefore, we chose to do a thorough examination of the pharmacokinetics of rEpo measured directly in brain tissues. These data improve our understanding of the pharmacokinetics of rEpo by establishing the profile of a single high dose given to neonatal animals.

To identify potential differences due to route of administration, it is helpful to compare the total exposure of the drug over time, the maximal drug concentration, and the corresponding half lives between i.p.- and s.c.-injected animals. In plasma, Epo increased after injection of $5000 \mathrm{U} / \mathrm{kg}$ rEpo in both i.p.- and s.c.-injected groups, and remained elevated for $24 \mathrm{~h}$ (Fig. 1). Intraperitoneal rEpo administration produced higher plasma concentrations ( $\uparrow$ AUC and $\uparrow \mathrm{Cmax}$ ) than did s.c. administration (Table 1). This is partially due to more rapid absorption for i.p. ( $\downarrow$ Tmax and $\uparrow C \max$ than s.c.). Correspondingly, the longer absorption time for s.c. ( $\uparrow$ Tmax and $\downarrow$ Cmax) may have contributed to the longer $\mathrm{t}_{1 / 2}$ for s.c. Overall, the relative fraction $\left(\mathrm{AUC}_{\mathrm{SC}} / \mathrm{AUC}_{\mathrm{IP}}\right)$ absorbed after s.c. injection was $84 \%$ of that after i.p. injection. Therefore, the majority of the difference in plasma Epo between s.c. and i.p. is probably due to the differences in absorption fractions and rates of absorption. Alternative explanations for differences between i.p. and s.c. concentration versus time curves would involve incomplete absorption or degradation of $\mathrm{rEpo}$ at the site of s.c. injection.

Control brain Epo concentrations (Fig. 2) are lower after s.c. than after i.p. administration. This corresponds well to the differences in s.c. and i.p. plasma concentrations. For example, comparing Tables 1 and 2, it is apparent that the Epo plasma AUC is $16 \%$ less, and control brain AUC is $14 \%$ less when comparing s.c.- to i.p.-injected animals. This proportional similarity in overall exposure between plasma and brain suggests that active transport at plasma concentrations below saturation levels or plasma concentration-driven diffusion are possible mechanisms of Epo passage across the BBB. Compared with plasma, changes in brain Epo after i.p. administration occurred more gradually, with brain Epo concentrations continuing to increase ( $\operatorname{Tmax}=10 \mathrm{~h}$ ) while i.p. plasma Epo was declining ( $\operatorname{Tmax}=3 \mathrm{~h}$ ). Note also that brain Epo declines to near $0 \mathrm{mU} / \mathrm{mg}$ protein by $24 \mathrm{~h}$ whereas plasma Epo is still above $1000 \mathrm{U} / \mathrm{mL}$. This point is in contrast to the one prior report that found detectable brain Epo $72 \mathrm{~h}$ post treatment (19).

After injury, brain Epo concentrations in the injured hemisphere were higher ( $\uparrow \mathrm{AUC}$ and $\uparrow \mathrm{Cmax}$ ) than those in the contralateral hemisphere (Table 2). After i.p. administration, the injured hemisphere is exposed to $50 \%$ more overall and double the peak concentration (105\% Cmax) compared with the contralateral hemisphere. After s.c. administration, the hemispheric asymmetry is less substantial, with a $4 \%$ increase overall and a $19 \%$ peak increase in the injured hemisphere. One possible explanation for the route-dependent differences in the penetration of rEpo into each hemisphere may be that 
BBB permeability is greatest soon after injury and BBB integrity is gradually restored. If this were true, then the rapid absorption of i.p. rEpo would also produce a greater penetration across the BBB during the window of permeability. Collectively, these data suggest that rEpo brain penetration is primarily driven by plasma concentration. This relationship is evident in the overall correlation between all Epo plasma data and all Epo brain data.

Several studies characterizing the pharmacokinetics of lower doses of rEpo used to treat anemia of prematurity in preterm infants have identified that rEpo kinetics may be nonlinear in infants $(20,21)$. Nevertheless, it may be useful to contrast the plasma parameters measured in preterm infants given a single s.c. dose of rEpo (400 U/kg) (22) with those reported in Table 1. In that study, plasma Epo remained significantly elevated $72 \mathrm{~h}$ after injection, $\mathrm{AUC}_{0-72}$ was 19,058, Cmax was $739.8 \mathrm{mU} / \mathrm{mL}$, Tmax was $7.7 \mathrm{~h}$, and $\mathrm{t}_{1 / 2}$ was $2.9 \mathrm{~h}$. In comparison to infants given $400 \mathrm{U} / \mathrm{kg}$ rEpo s.c., neonatal rats given $5000 \mathrm{U} / \mathrm{kg}$ s.c. exhibit a 6-fold increase in total exposure, 8 -fold increase in peak, and a 2.9-fold increase in $t_{1 / 2}$ for plasma rEpo kinetics.

In summary, this report demonstrates that systemic administration of high-dose rEpo results in a slow increase in brain Epo concentration in both normal and brain-injured neonatal rats. The i.p. route of rEpo administration produced a higher plasma Epo concentration more rapidly, with correspondingly greater penetration into the brains of brain-injured animals. Overall, however, the total body exposure to rEpo, as measured by plasma AUC, was similar with both routes. Like i.p. administration, the i.v. administration of rEpo results in rapid attainment of high peak concentrations. These data provide some insight into plasma Epo concentrations that can be considered neuroprotective. Based on previously published neonatal animal studies, $5000 \mathrm{U} / \mathrm{kg}$ rEpo is neuroprotective $(17,18,23,24)$. We demonstrated that this dose, when given i.p. or s.c., results in peak plasma concentrations ranging from 6,000 to $10,000 \mathrm{mU} / \mathrm{mL}$. Further studies are needed to determine the safety and pharmacokinetics of high-dose rEpo in human infants.

Acknowledgments. The authors thank Michelle Chan for her technical assistance.

\section{REFERENCES}

1. Sunshine P 1997 Epidemiology of perinatal asphyxia. In Stevenson DK (ed) Fetal and Neonatal Brain Injury. Oxford University Press, Oxford

2. Aylward GP 2005 Neurodevelopmental outcomes of infants born prematurely. J Dev Behav Pediatr 26:427-440

3. Ferriero DM 2004 Neonatal brain injury. N Engl J Med 351:1985-1995

4. Vannucci RC, Vannucci SJ 2005 Perinatal hypoxic-ischemic brain damage: evolution of an animal model. Dev Neurosci 27:81-86

5. Vannucci RC, Brucklacher RM, Vannucci SJ 1997 Effect of carbon dioxide on cerebral metabolism during hypoxia-ischemia in the immature rat. Pediatr Res 42:24-29

6. Vannucci RC, Lyons DT, Vasta F 1988 Regional cerebral blood flow during hypoxia-ischemia in immature rats. Stroke 19:245-250

7. Aher S, Ohlsson A 2006 Late erythropoietin for preventing red blood cell transfusion in preterm and/or low birth weight infants. Cochrane Database Syst Rev 3:CD004868

8. Juul S 2002 Erythropoietin in the central nervous system, and its use to prevent hypoxic-ischemic brain damage. Acta Paediatr Suppl 91:36-42

9. Juul SE, Yachnis AT, Christensen RD 1998 Tissue distribution of erythropoietin and erythropoietin receptor in the developing human fetus. Early Hum Dev 52:235-249

10. Grasso G, Sfacteria A, Cerami A, Brines M 2004 Erythropoietin as a tissueprotective cytokine in brain injury: what do we know and where do we go? Neuroscientist 10:93-98

11. Juul SE, McPherson RJ, Farrell FX, Jolliffe L, Ness DJ, Gleason CA 2004 Erythropoietin concentrations in cerebrospinal fluid of nonhuman primates and fetal sheep following high-dose recombinant erythropoietin. Biol Neonate 85:138-144

12. Ehrenreich H, Hasselblatt M, Dembowski C, Cepek L, Lewczuk P, Stiefel M, Rustenbeck HH, Breiter N, Jacob S, Knerlich F, Bohn M, Poser W, Ruther E, Kochen M, Gefeller O, Gleiter C, Wessel TC, De Ryck M, Itri L, Prange H, Cerami A, Brines M, Siren AL 2002 Erythropoietin therapy for acute stroke is both safe and beneficial. Mol Med 8:495-505

13. Lappin TR, Maxwell AP, Johnston PG 2002 EPO's alter ego: erythropoietin has multiple actions. Stem Cells 20:485-492

14. Juul S 2004 Recombinant erythropoietin as a neuroprotective treatment: in vitro and in vivo models. Clin Perinatol 31:129-142

15. Bauer LA 2001 Applied Clinical Pharmacokinetics. McGraw-Hill, New York, pp 3-90

16. Keller M, Yang J, Griesmaier E, Gorna A, Sarkozy G, Urbanek M, Gressens P, Simbruner G 2006 Erythropoietin is neuroprotective against NMDA-receptormediated excitotoxic brain injury in newborn mice. Neurobiol Dis 24:357-366

17. Chang YS, Mu D, Wendland M, Sheldon RA, Vexler ZS, McQuillen PS, Ferriero DM 2005 Erythropoietin improves functional and histological outcome in neonatal stroke. Pediatr Res 58:106-111

18. Dzietko M, Felderhoff-Mueser U, Sifringer M, Krutz B, Bittigau P, Thor F, Heumann R, Buhrer C, Ikonomidou C, Hansen HH 2004 Erythropoietin protects the developing brain against N-methyl-D-aspartate receptor antagonist neurotoxicity. Neurobiol Dis 15:177-187

19. Sun Y, Zhou C, Polk P, Nanda A, Zhang JH 2004 Mechanisms of erythropoietininduced brain protection in neonatal hypoxia-ischemia rat model. J Cereb Blood Flow Metab 24:259-270

20. Veng-Pedersen P, Widness JA, Pereira LM, Schmidt RL, Lowe LS 1999 A comparison of nonlinear pharmacokinetics of erythropoietin in sheep and humans. Biopharm Drug Dispos 20:217-223

21. Widness JA, Veng-Pedersen P, Peters C, Pereira LM, Schmidt RL, Lowe LS 1996 Erythropoietin pharmacokinetics in premature infants: developmental, nonlinearity, and treatment effects. J Appl Physiol 80:140-148

22. Melo AM, Costa MT, Porta V, Vaz FA 2005 Clinical pharmacokinetics of lyophilized recombinant human erythropoietin-alpha following single-dose subcutaneous administration in premature newborns. J Matern Fetal Neonatal Med 17:55-58

23. Matsushita H, Johnston MV, Lange MS, Wilson MA 2003 Protective effect of erythropoietin in neonatal hypoxic ischemia in mice. Neuroreport 14:1757-1761

24. Kellert B, McPherson RJ, Juul SE 2007 A comparison of high dose erythropoietin treatment regimens in brain injured neonatal rats. Pediatr Res 61:451-455 